\title{
Augmented and Humble: Spaces for Social Responsibility Learning in Architectural Education
}

\author{
SARA KHORSHIDIFARD \\ Drury University
}

The profession and beforehand the education of architecture remains accountable and must increase responsiveness towards real-time needs, including those of society. This paper examines this necessity, asserting a more rigorous and expansive application and address of social responsibility learning in the education. Architecture professionals have advantaged positions as creative generators of built environments, hence, are socially responsible to serve the public good, empowering peoples and envisioning democratic places for all. The education is the starting place in transferring the essential learning principles, knowledge, and skills. Despite the import, social learning is still one of the least considered, most overlooked student performance criteria in architectural education. This is despite several contemporary mandate assertions in place and progress by leading professional organizations such as AIA and educational credentialing bodies such as NAAB. The paper considers as premise that, despite all the good, social learning still remains a key area that design pedagogy tends to overlook rather easily or can fall short to address. Regarding The Now, where loftier curriculum revisions and augmented experiences may not be within the reach of a program, humble opportunities always remain within reach, opening rooms for significant civic goals. The paper is highlighting some of these more nuanced and subtle opportunistic approaches to embrace and better address the social in the education.

\section{THE PROFESSION AND THE EDUCATION}

More than half a century is passed from the time when the civil right leader Whitney Young, in an AIA keynote address in 1968, criticized the profession of architecture for its deficiencies of civic contribution, muteness and irrelevance to society. Since then, architectural education is continuously reminded by other like-minded individuals of its social and civic purposes. The education is prompted to produce multivariate good world citizen graduates who are intellectually mature, ecologically sensitive and socially responsible. Perhaps, enculturating such an ideal community of alumnus is easier said than done. Architecture, without doubt, both as profession and education remains highly demanding regarding the competencies required and desirable for gaining the knowledge and skills for conducting complex syntheses of all that design entails. Having always been performing in close relations to society, the field requires continuous re-examining of its mission and curricula to better correlate its education with societal plights. Overarchingly exploring complexity and multidimensionality in design pedagogy, the study considers social responsibility learning to be a relatively under-explored dimension of the education. Highlighting the necessity for its stronger integrations, the paper is arguing that, notwithstanding of whether that could be through "augmented" or "humble" experiences, it is key to nurture and expand the application and address of this learning dimension in the education. This positionality is critical Now, no matter what and with all it takes, despite limitations of circumstances or educators abilities in given contexts.

Design studio pedagogy is likely to miss out on social learning. Limitations in part relate to the depth and breadth with which the learning is to be addressed or achieved based on a program's curricular or accreditation requirements. This study acknowledges an awareness of the fundamental changes currently underway in direction of full implementation in National Architectural Accrediting Board's (NAAB) 2020 Conditions for Accreditation. At the same time, this paper views worthy of evaluation a look at social responsibility learning standards in its predecessor, the 2014 Conditions for Accreditation. Under the 2014 conditions, to assist programs with preparing performance reports, evaluation criteria include Community and Social Responsibility as one of five Key Perspectives (12). The other four perspectives include: Collaboration and Leadership, Design, Professional Opportunity, and Stewardship of the Environment. The related perspective states that "architects can create better places" and "design can create a civilized place by making communities more livable." Henceforth, the conditions assert that a program's integration should embrace "nurturing a calling to civic engagement to positively influence the development, conservation or changes to the built and natural environment." (17-18) This perspective prompts pedagogical responsibilities to educate for learning outcomes contributing to well-being of citizens, and to be aligned with those, programs include research, practice, and education to encourage community building, social responsibility, and civic engagement locally, regionally, and globally. 

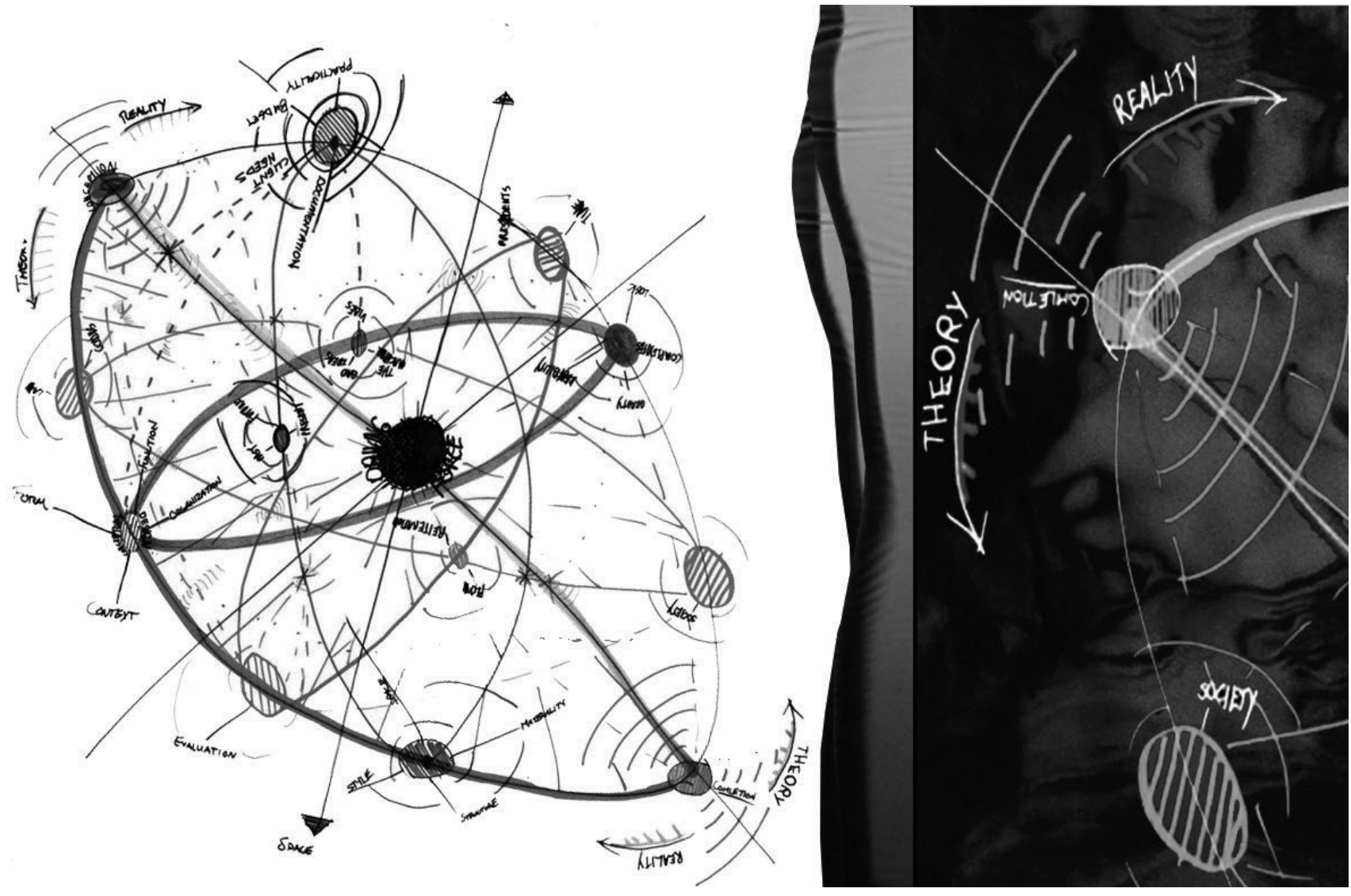

Figure 1: Teaching a section of the ARCH 420: Architectural Design II studio at the University of Wisconsin Milwaukee's School of Architecture and Urban Planning in spring 2012, I had decided to pre-assess my students' knowledge on quintessential components of design process. The above concept-map is the outcome of a group of the students, attempting to represent the design process with intricate non-linear connections integrating axes factors of time and space. Starting off by debating over symbolic uses of an atom or a galaxy, the group ultimately decided on galaxy as their metaphor. The group first drew the "time" axis from the "conception" to the "completion" of a project at both ends. The realities and speculative dimensions got involved in a nonlinear fashion as planets. The group then marked the "space" axis intersecting with the "time." Essential knowledge spheres were clustered dynamically, flowing in the galaxy as interconnected nodes with back-and-forth linkages. Zooming in closer, one can observe a more isolated orange planet on the bottom right that is marked as the "society." It appears further undefined with a lesser elaborated connectivity. Clearly, in students' initial perceptions, the role of society or social dimensions was feebler compared to the other extents.

Despite Five Perspectives having been playing out relatively well, being distributed throughout the 2014 version and its twenty-six required Student Performance Criteria, only one single category is explicitly defined based on descriptive contents of Community and Social Responsibility, and that is: "A.8. Cultural Diversity and Social Equity." Related to this SPC, programs are required to educate learners on broad understandings "of the diverse needs, values, behavioral norms, physical abilities, and social and spatial patterns that characterize different cultures and individuals and the responsibility of the architect to ensure equity of access to sites, buildings, and structures." As much as A.8 could assuredly inspire curricula, it has not been specific enough or advantageous in terms of social learning, only prompting broad, non-descript expectations for the programs.

Despite relatively loose provisions in social learning standards, on the one hand, some programs gain the abilities to go above and beyond. Usually more privileged in that regard, those programs either possess additional resources and faculty with focused interests in social dimensions to carve out more intricate curricula or are altogether joined with in-house community planning and design centers. Some, likewise, complementarily offer minors and additional certifications related to community development or Public Interest Design. On the other hand, however, it is not all existing programs that have cultural means or directions to adopt and allocate additional efforts to enhance social dimensions of learning in architectural education. Conversely, it is more likely for a typical program to stay behind. Those are often ones that have little to no bonus resources, curricular prospects, or even any formal merit, and tenure and promotion provisions to motivate individual faculty to embrace socially-engaged research agendas.

Regarding The Now, when LESS TALK and MORE ACTION is essential, anywhere loftier curriculum revisions are not within the reach of a program, what are some tangible opportunities 


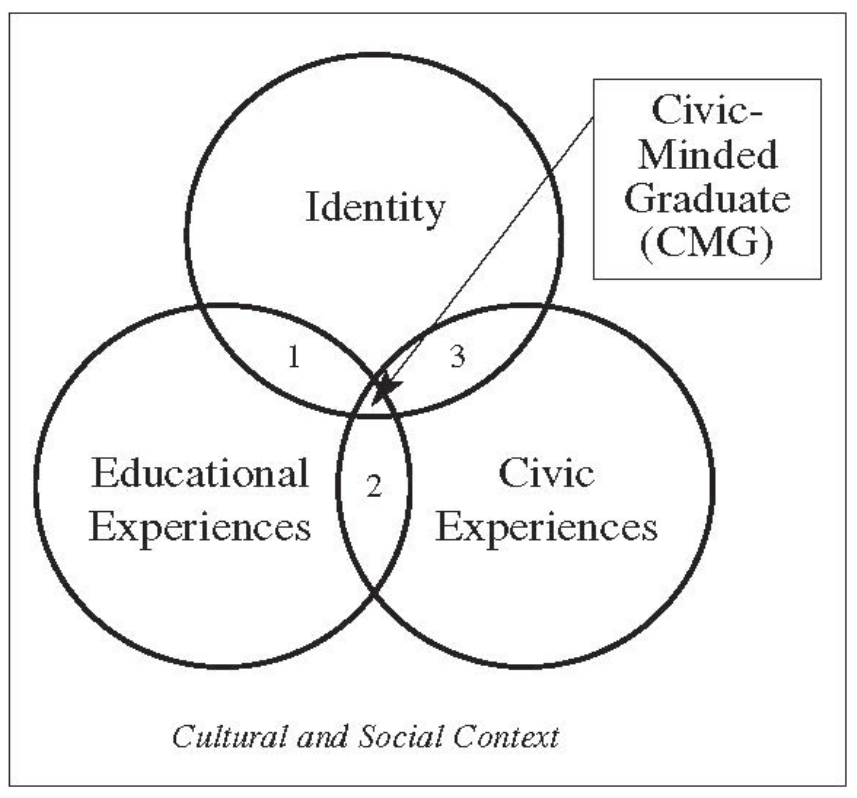

Figure 2: The Center for Service and Learning at Indiana UniversityPurdue University defines the Civic-Minded Graduate (CMG) as: "a person who has completed a course of study and has the capacity and desire to work with others to achieve the common good. It refers to a person's inclination or disposition to be knowledgeable of and involved in the community and to have a commitment to act upon a sense of responsibility as a member of that community." In the Venn diagram above, the Identity realm signifies personal self-understanding, self-awareness, and self-concept, the Educational Experience relates to academic gains and skills deriving from curricular and co-curricular experiences, and the Civic Experiences component indicates how a person actively engage in the community doing advocacy, leadership, and service in the community.

that can open rooms for civic goals? What are some further nuanced, subtle, or opportunistic approaches that help address social learning in architectural education? How can the education teach with ways of staying loyal with integrity to its better conventions while humanizing its apprentices: enabling learners to work better with others across difference, acquire civic identity, actively participate in society to address civic issues, and ultimately orient social change? Can all these be learned or is it too much to ask from architecture? In light of these questions, this paper engages both challenges and opportunities optimistically, seeking ways to fit civic learning within the bounds of existing, standard pedagogies of typical programs. As feasible remedies to amend and enhance the embedment of the social and embodiment of its learning processes and outcomes, the content investigates tactical modifications and smaller-in-scope, course-based decisions, which could occur, if nothing else, but, always, no matter what.

\section{A PUBLIC FOCUS}

No long ago, higher education has reframed its public purpose and fundamental shifts have taken shape in its mission, structure, essence of faculty work, and civic learning outcomes (Boyer 1994). The new vision has emphasized civic engagement programs, putting community-based learning at the center of research and practice in higher education. ${ }^{1}$ Civic learning dimensions have been organized into seven paradigms: civic professionalism, social responsibility, social justice, connected knowing: ethic of caring, public leadership, public intellectual, and engaged/public scholarship (Battistoni 2017). ${ }^{2}$ Despite the specific skills and knowledge associated with each of these, a common element extracted is civicmindedness (Steinberg, Hatcher, and Bringle 2011, 20). ${ }^{3}$ Even with varying levels of disciplinary understandings, civic orientation is framed as a foundation to most disciplines; hence, developing civic-minded graduates has become a fundamental purpose of higher education. ${ }^{4}$ (Figure 2)

Where does architecture as a discipline stand with regards to the new public purpose? Regarding The Now and MORE ACTION, how close is the architectural education to the standard rigor demanded in the new model of the higher education? Kramer's (2012) definition of social responsibility delivers a feasible curricular framing tool, offering four particular aspects of the learning: sustainability and environmentally-responsible design, considering the needs of local communities and the wider public, ethics or ethical implications of design decisions regarding social, political, environmental and cultural issues, and civic engagement through public service in the practice of architecture (296297). ${ }^{5}$ AIA has also identified the role of a Citizen Architect, members who apply their design insights, talents and training to advance leadership, advocacy, and civic engagement, and within their community, strive to be the voice of the profession to other members in the general public. Theoretically, the definition can further the professional mission. By going beyond the required tenets of a licensed architect and commitments in protecting the health, safety, and welfare of the general public, a Citizen Architect would likewise consider how architecture can more meaningfully impact communities and environments. Looking back, Samuel Mockbee and the Auburn's Rural Studio program and its accomplishments has, undoubtedly, set the bar high on augmented versions of social learning agendas in architecture schools. Rural Studio has offered a superlative ground for cultivating the social, graduating Citizen Architecture Students who can use their skills in benefit of society.

A holistic gaze at the national landscape of the architecture curricula is beneficial, revealing the ways in which various programs engage smaller and larger possibilities for students' gains of social learning experiences. Referring back to the frameworks in the article's beginning section, drastic changes are now underway for full implementation within the currently drafted, NAAB 2020 Conditions for Accreditation document. New conditions will undoubtedly result in new stresses for the programs requesting or maintaining accreditation. Yet, setting upcoming changes 


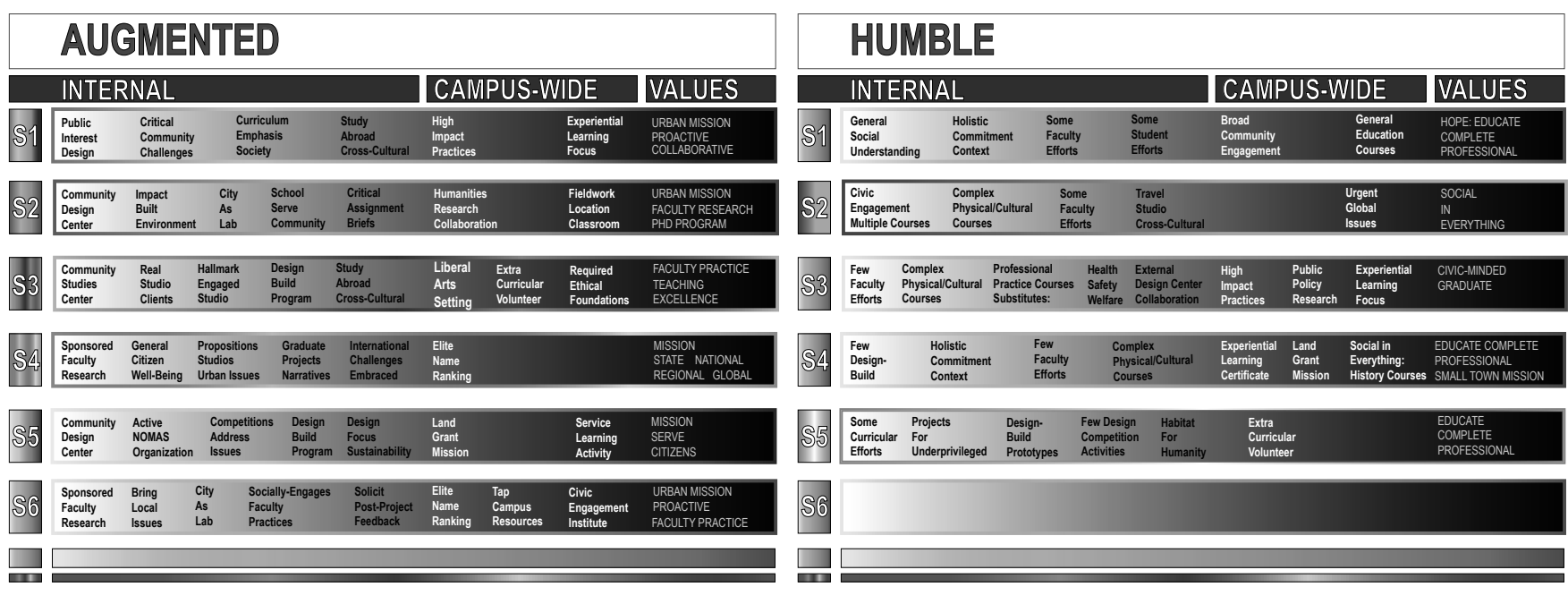

Figure 3: Annotated tables draw a representational image of the landscape of social responsibility learning from the NAAB APR documents that are publicly available through simple web search. Anonymous and selective (non-inclusive of all schools), table concepts have resulted from evaluations and interpretations of the "Community and Social Responsibility" perspective narrative written into some APRs. Found online, and having been submitted for accreditation between 2014 and present, the particular perspective's narrative can reveal similarities in the sense of the repetitive patterns as the degrees to which the social learning category has been targeted and invested upon in a program, moreover, as to whether the created experiences are augmented or humble.

aside, the 2014 conditions have been and will remain in operation as the basis until 2020. Particularly relevant to this study's focus is Architectural Program Reports' written sections on one of the Five Perspectives: "Community and Social Responsibility." Therefore, the study evaluated and interpreted the narrative in a number of publicly-available APRs that have been submitted for accreditation since 2014. A beneficial data source, essentially, is how programs clarify their integration of the perspective as a way to not only expose views and stances on social leaning, but also degrees to which learning components are engaged in their curricula. ${ }^{6}$ (Figure 3 )

\section{HUMBLE STRATEGIES, PROMISING OUTCOMES}

Actionable and tactical solutions as toolkit for faculty can help enhance essential civic learning within existing bounds of even most standard programs and pedagogies. The following thematic reflections on past successes summarize a few viable remedies to mend and amend social learning processes and outcomes. This is a way to post-theorize by reflecting on teaching practices over a five-year span in a small program of architecture with heavier technical focus and no room in the curriculum for teaching social responsibility learning. Extractions are concrete basing on already-happened studio experiences in a standard program. It is to argue that some of such humble, smaller-in-scope, and course-based modifications, if best incorporated into the studio and supplemented with community-based design, can make a difference in enhancing social learning experiences. When no augmented experiences could be possible, humble strategies must subsist for success.

\section{RIGHT INFORMATION, RIGHT TIME:}

The right information at the right time can make all the difference for students. Information-seeking remains at the core. A transparent design process with pedagogies capably unifying "design" with "research" is seen as a way to balance design with rationalism. In support of equilibrium between the known-as binaries of "rationality" and "creativity," clearer mapping of essential research dimensions required at each stage is advantageous. Highlighting major to-be-considered extents as key informing forces is anticipated with high impact on designresearch outcomes. Overall, progressive demands regarding rigor of investigations are beneficial; a seemingly no-brainer, research is still deeply lacking in standard studio pedagogies. An essential component, for instance, can be particular attempts in revealing complex social structures of power in sites and contexts as critical forces. In summary, maintaining continuous information flows, where each module is engaged when it exactly should according to expert standards, and guiding the to-be-sought-after evidence typologies as moving to a next step is crucial in the success of the design process. Furthermore, valuable are expositions of diverse knowledge possibilities from a variety of multi-disciplinary standpoints. Combined with information sessions with community groups and other engaged interaction possibilities, the knowledge domain can altogether help in furthering the learning about diverse user needs. If conceivable, it is enriching to cultivate more options for conducting hands-on engagement with com-munities relevant to project topic and ask for reflective pieces on experiences. As an instance, intentional and targeted community-service hours at a community kitchen and a food pantry were invaluable, early on and at primary stages while students were in ideation phases. (Figure 4). 


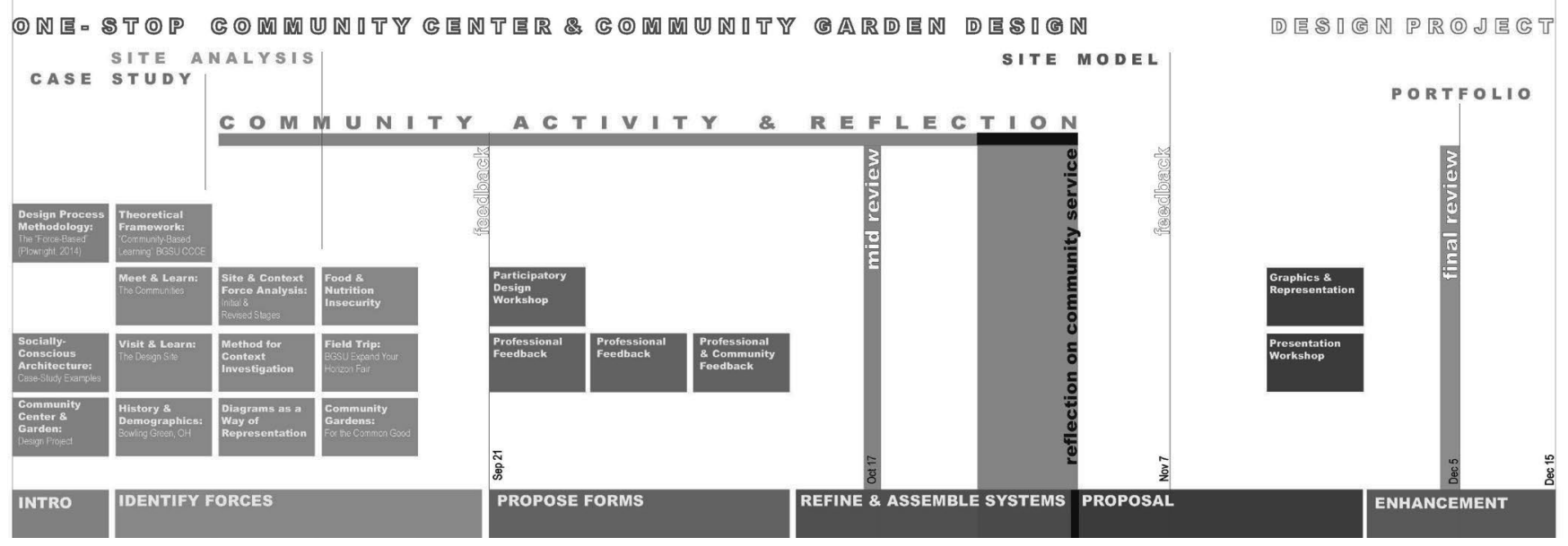

Figure 4: This scheme renders essential mapping of semester-long experiences with the ability to compartmentalize required realms of information. Putting words and concepts out plainly assisted students in making knowledgeable decisions based on social dynamics considerations at each stage. Furthermore, holding on to a single faculty-prescribed and explicit design methodology at hand, in this case based on forces, offered focal clarity and opened other emphases spaces for social learning. On the top of reducing potential confusions about the how-to of design, the imposed order made feasible to achieve objectivity in outcomes, directed by design-research and making use of collected evidence. The stress on the how-to ultimately helped generate a rational and process-driven studio environment where form-making and object-creation automatically became not the first, but a second thought.

\section{ONE EXPLICIT METHOD, AT HAND:}

Prescribing and reinforcing through discussions a single, given design methodology bids procedural clarity for students. This can better converge their attentions to rigor of enquiry and essential forces, specially, ones related to society and social learning. (Figure 4). One applicable strategy is the "forcebased design (Plowright 2014)." 7 As community-based components can add issues of indeterminacy to pedagogy, any complexifying of the design process could diffuse further confusion for novice students. Due to a nature of civic engagement procedures, mainly, with courses directly engaging the publics, a class may necessitate continuous instructional design and pedagogic decision-making up to the end. Furthermore, demands for modifications on-the-go may involve learners' pre-knowledge or the lack so, therefore, rising needs for improvisation and compromise in a semester. An applied method such as the force-based can contribute momentously by increasing procedural stability in learning expectations, hence, allowing effective taming and management of rising complexities. With all indeterminacies, a true, solid, and enduringly-transparent, prearranged design method acts as a point of fixity, assisting as organizational tool throughout the entire semester.

\section{A PUSH-PULL STRATEGY, BETWEEN REAL AND SURREAL:}

An actual built environment setting as a context for a sociallydriven, community-engaged project can often carry with it a gloomy weight from economic, political and socio-spatial issues faced by residing communities. Students, on the one hand, who have been trained, hitherto, in architecture, mainly on ways of engaging creative and practical thinking realms are now tasked with substantial critical thinking assignment for a given, stifled social situation. At this point, they ought to grapple unceasingly with a sundry of contextual limitations and constraints, beyond which being a mounting pessimism and glumness stemming from the real issues of a deprived community. Students may be carried away, getting more easily discouraged to use their previously-internalized, abstract architectural sensibilities, assuming no hope or ideal could be possible considering real lacks of resources. The situation may lead to a full surrender to real issues, eventually, leading a cliché or unsophisticated design response. In sum, dimness of realities involved can box in students thinking and limit their imagination for speculations to a most minimal and apparent possible. This could be especially true when intense collaborative goal-setting and community-engagement events are part of the process, using techniques such as design charrettes or design games, where there is direct interaction with community members voicing opinions. Students who may be having a harder time grasping contextual complexities may also tend to over-simplify the design situation, acting by lowering architectural aptitudes and compromising design intentions to fully satisfy the members. A resulting pitfall may be a lack of synthesis and the filtering of ideas through professional lenses. A pedagogical solution for pushing design speculations and cultivating optimistic design-future thinking is to begin the course, not with the community project, but, by pitching a rather surreal assignment prompt. This could be shorter, perhaps, a utopia-driven assignment to be completed prior to the real community project, and be somewhat related thematically to the main project in terms of issues or community situation. 


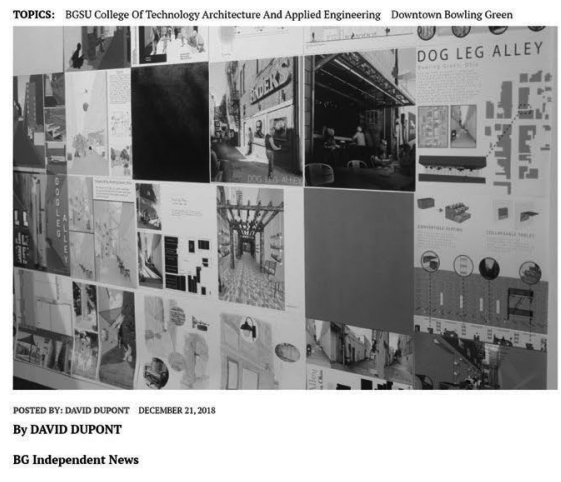

CAMPUS, DOWNTOWN

BOWLING GREEN

DECEMBER 21, 2018

BGSU

architecture

students aim to

teach downtown's

Dog Leg Alley

some new tricks

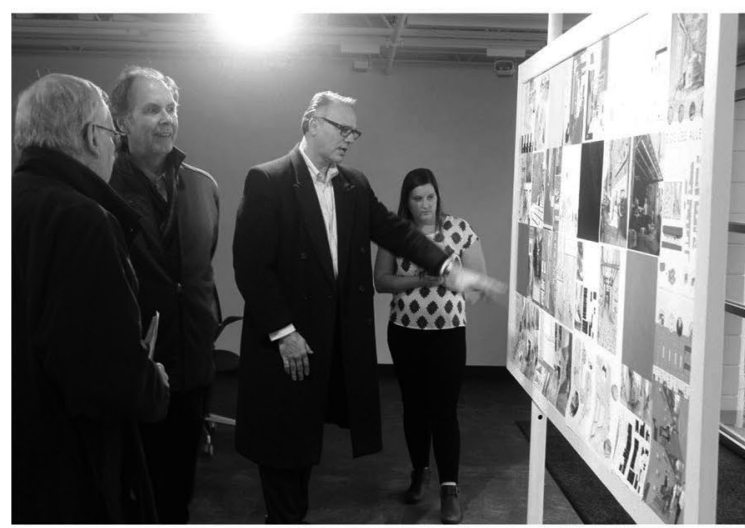

Figure 5: Outcomes of a short community project was exhibited during a typical final studio review session and received local news recognition.

Stretching mental capacities, extending those into surreal platforms and then releasing the minds from those imaginaries back to concrete, generates an elastic pedagogy. Embracing the elasticity can be gainful, subscribing broader spectrums of schematic palettes and diversity. Considered likewise as implicit mapping of instructor expectations for student deliberations of higher quality speculations, the elasticity can boost in design quality. The distinct push-andpull gamut creates interstitial learning spaces between the real and surreal, perhaps, a way to exercise drifts between the extremes such as utopian thinking and public policy. To say, students can learn to formulate wistful solutions capable of operationalizing most wishful speculations.

\section{SHOW THE WORK, CELEBRATE THE SMALL:}

Contextual circumstances can lead to modest pedagogical agendas in prospectus regarding social learning. As a result of circumstantial humble applications and directions, progress and success in terms of impacts in the community may appear faded or almost always insignificant. In humble settings, it can be less plausible to observe any direct and grander effects from the hard work of a faculty for an engaged, socially-tuned class activity in the course of a semester, or even so in the spans of a faculty-in-charge's tenure. Knowing also that social dimensions of learning in the field of architecture have not been valued as high or significant, or at least as key motivation in program accreditation, civic engagement components in courses could be one of the first aspects to be easily pushed away and sidelined. Furthermore, this is so as it can become lesser rewarding or even discouraging for the faculty not wanting to pursue such efforts after a while, realizing an immensity of required communication efforts with not much impact or acknowledgement. However, towards this end, the paper dues that any achievements, even supposing small, deserve to be cherished and successes, even if slight, warrant credit. In this manner, (pro)active role-playing is needed to expose the exertions, one way, by reaching out to interested on-campus and external entities such as local news organizations to facilitate bringing to surface some of the pedagogical values and invisible outcomes. (Figure 5).

\section{FINAL THOUGHTS}

As the conference theme set into focused attention, despite restored deeds of professional practice in realizing inexorable and universal values of "collaboration" in the world today, architectural education remains aloof, still rooting for "master student" dynamics. Part of the needed positive shifts in the education can come true by acting on to cultivate critical thinking abilities of the desired collaborative minds. This could involve stronger focus on public engagement, and, key feature to that, further active, diverse and genuine participation being entrenched in the curricula. ${ }^{8}$ In addition to the discipline's internal plights, some of which set by the conference, the twenty-first century is posing new challenges and opportunities to both the profession and education of architecture. For architecture, to be more impactful and relevant, cyclical re-imaginings are needed, one way, by opening up, more than before, for building solider bridges to natural sciences, social sciences, and humanities. Especially significant in enhancing social responsibility learning outcomes are to imagine new conduits for vigorous socialscience collaborations, altogether, reinforcing the role of space, place, and architecture in betterments of societies.

With shifting global dynamics, imagining an ideal world can become a powerful tool for enhancing proactivity and leading structural transformation, or, the least, avoiding mounting senses of helplessness and despair. Considering utopian thinking as activism, there could is a place in the education for the ambitious vision of educating complete professionals who are not only equipped with the tools to comprehend the greater society in its entirety, but also to identify how their architectural training, thinking and makings can become transformative, carrying expedient tactics for generating architectures to be making much difference. Educating uses of design in addressing critical challenges faced by communities also demands more comfort with bringing acute "wicked problems" to classroom. Wicked problems are inherent in systems where every problem is linked to and inextricably interacts with others and the systems' messes are too complex and difficult to be resolved by single entities. ${ }^{9}$ 
As new shifts are now incubating, with novel directions now morphing the NAAB's 2020 Conditions and Procedures for Accreditation, matters could be taken in both directions regarding social learning dimensions. Hitherto, quick views of the drafted documents may reveal lesser emphasis on SPCS as items that have been the unbending focus of the 2014 version. The new version, however, offers more concentration on program values and ways of bringing unique niches. It ought to become dilemmatic at a point, likely and unlikely, that with the changes, programs could more easily initiate efforts to integrate social and civic purposes more methodically as part of their curriculum, or decide not to, because those are not weighed enough to be "disciplinary" values. Only time is evidence to anticipated results; may time prove collective spirits of the discipline moving to virtuous directions.

\section{ENDNOTES}

1. Boyer, Ernest L., "Creating the New American College." (1994): A48.

2. Battistoni, Richard M., Civic Engagement Across the Curriculum: A Resource Book for Service-Learning Faculty in all Disciplines. Stylus Publishing, LLC, 2017.

3. Steinberg, Kathryn S., Julie A. Hatcher, and Robert G. Bringle. "Civic-Minded Graduate: A North Star." (2011).

4 In addition to Steinberg, Hatcher, and Bringle's (2011) synthesis, key concept in the following literatures is also a focus on nurturing civic-mindedness:

Sullivan, William M., and Matthew S. Rosin. A New Agenda for Hgher Education: Shaping a Life of the Mind for Practice. Vol. 14. John Wiley \& Sons, 2008.

Sullivan, William M. "Work and Integrity: The Crisis and Promise of Professionalism in America." (1995).

Colby, Anne, Elizabeth Beaumont, Thomas Ehrlich, and Jason Stephens. Educating citizens: Preparing America's Undergraduates for Lives of Moral and Civic Responsibility. Vol. 6. John Wiley \& Sons, 2003.

5. Kramer, Kimberly., "Social Responsibility in Architectural Education." American Transactions on Engineering \& Applied Sciences 1(3). (2012): 295-317.

6. As NAAB calls, the programs must show how they are "nurturing a calling to civic engagement to positively influence the development, conservation or changes to the built and natural environment. Addressing this perspective could include examples of public and community projects/programs outside of coursework, or as structured elements within coursework (NAAB 2014, 17-18)."

7. Plowright, Philip. Revealing Architectural Design: Methods, Frameworks and Tools. Routledge, 2014. This method frames a rational design process through systems thinking and focused on negotiations between "forces," which are categorized as pressures, assets, constraints, and flows. "The point of the framework is to make those forces accessible and ordered so a designer can act upon them. System thinking avoids the construction of pre-existing rules and sees the design of the physical environment as the result of forces and the application of principles. (40)." Therefore, "... architectural form is the result of the resolution of forces, whether physical, environmental, or social (42)."

8. Sanoff, Henry. Community Participation Methods in Design and Planning. John Wiley \& Sons, 1999. As Sanoff puts, "participation means the collaboration of people pursuing objectives that they themselves have defined $(\mathrm{x}) . "$

9. As Rittel \& Webber (1974) and Churchman (1967) identified in their original text, wicked problems are ill-formulated social system problems in which the information is confusing, which involve several clients and decision makers with possessed conflicting values, and in which implications in the whole system are painstakingly perplexing.

Rittel, Horst WJ, and Melvin M. Webber. "Wicked Problems." Man-made Futures 26, no. 1 (1974): 272-280.

Churchman, C. West. "Guest editorial: Wicked Problems." (1967): B141-B142. 